\title{
18 Copyright issues of Chinese films adapted from the Internet literature
}

\author{
Guanqun Gao
}

With the rise of online literature, more and more original works, such as online novels and screenplays have been adapted to the big screen. Many online literary works have won both popularity and high box office receipts for their cinematic adaptations. At the same time, many legal issues have arisen, such as contract disputes, plagiarism, and infringement in the process of pre-production, production and post-production, all of which originated from the copyright of online literary works. The industrialization of online literary works and films requires a good industrial environment and a set of reasonable copyright dispute resolution mechanisms.

\section{Overview of Chinese cinematic adaptations of online literature}

\section{Definition of online literature}

Online literary works refer to literary texts, practical texts and discourse texts represented on Internet media platforms through computer technologies, such as hypertext links and multimedia interpretation. Text types could include poems, plays, novels, biographies, news survey, essays and prose, etc.

\section{The connotations of Chinese cinematic adaptations of online literature}

According to Article 10, the 14th item of the Copyright Law of the People's Republic of China, "Adaptation right is the right to adapt a work and to create an original new work." The adaptation right is a kind of property right, rather than a personal right. The adaptation of Internet literary works to the cinema involves transforming words into audio-visual language on the big screen, thus it becomes an original new work.

Films adapted from online literature create a new form of text media communication. The rich expression of cinematic language provides a broad space for online literature. The fact that the work originally appeared online also provides its cinematic adaptation with a large number of existing fans and guarantees good box office. Many online literature readers are willing to watch the adapted movies, so the filmmakers can save huge costs for publicity. The 
low cost of adapting online literary works is an important factor considered by the filmmakers.

\section{The development of cinematic adaptations of online literature}

Emerging development period (pre-2000)

In 2000, the film Flyn' Dance, made by Shanghai Film Studio, was the first online literary adapted film in China. In the 1990s, Cai Zhiheng (net name: Pzi Cai) serialized the online novel Flyn' Dance in Taiwan's BBS community which gained huge popularity after its publication in Mainland China. Shanghai Film Studio purchased its cinematic adaptation rights, featuring celebrities such as Chen Xiaochun and Shu Qi in this film, which started the historical process of online literary adaptation in China. In 2001, the online literary work Beijing Story, a homosexual theme novel, was adapted by the director Guan Jinpeng into the film Lan Yu, starring Hu Jun and Liu Ye. The film won five awards at Taiwan's Golden Horse Film Festival and achieved great success. In the following years, the genres and quality of online literary works continued to improve, yet the cinematic adaptation of online literary works had not yet become a significant phenomenon.

\section{The period of rapid development (2010-2014)}

During this period, the number of films adapted from online literature grew rapidly and the quality of such adaptations continued to improve. The genres are mostly romance for young audiences, such as To Our Youth That Is Fading Away and Fleet of Time.

Many excellent online literary works have provided creative material for Chinese filmmakers and even well-known directors such as Chen Kaige also started making films adapted from online literary works.

\section{The in-depth development period (2015-present)}

The State Administration of Press, Publication, Radio and Television issued notices on the promotion of outstanding original online literary works for four consecutive years from 2015 to 2018. The selection and promotion of outstanding online literary works reflected the government's attention and support for the online literature market. This promoted the development of films adapted from online literature, and the genres of films adapted from online literature have also become diverse. At the same time, the three Internet giants - Baidu, Tencent and Alibaba - proposed a strategy of "Internet + Movies." Based on the Tencent video website, Tencent developed high-quality literary works to create a "Tencent Movie +" film and television platform. Baidu established Baidu Literature. By purchasing Chinese reading websites such as Zongheng China and 91 Panda Reading, and by focusing on the 


\section{Guanqun Gao}

copyright of original online literary works, it integrated Baidu's video and audio platforms, such as iQiyi, to create a full film industry chain. Alibaba has invested in Youku video website and film production companies, etc. and focused on Internet financial capital to establish the film industry. At this stage, with the promulgation and implementation of the supporting policies from the government, the external environment for adapting films to network literature was improving. With the arrival of the multi-network convergence era of telecommunications networks, radio and television networks, and computer communication networks, the film industry has opened a new development stage.

\section{Reasons for the phenomenon of cinematic adaptation of online literary works}

\section{To provide high quality scripts to the film industry}

A good screenplay is essential to a movie. In China, the role of screenwriters in the entire film industry is constantly marginalized, compared to that of directors or producers. On the one hand, the lack of excellent screenwriters, and the time-consuming and high cost of developing original film scripts have led to a serious shortage of high-quality screenplays. On the other, there are enormous amounts of online literary works of various stories. Screenwriters can extract high-quality novels and adapt them to movie scripts. Many online literary works are already well established in terms of story and artistic/commercial values, which is convenient for screenwriters when making decisions for cinematic adaptation. Thus, online literary works are one major source to solve the problem of the shortage of scripts in the film industry.

\section{Guarantee of high movie box office receipts}

For film production companies, the box office is the essential criterion for judging the success of a movie. The high popularity of high-quality online literary works provides a guarantee of its cinematic adaptation's box office. Generally speaking, the bigger the influence of online literary works, the more audiences the cinematic adaptations will have. For example, the movie Cry $\mathrm{Me}$ a Sad River, which was released in September 2018, focuses on the theme of campus bullying. It was adapted from Guo Jingming's best-selling online novel of the same name. With huge popularity, the film's box office went all the way up the rankings, and finally the film achieved 0.35 billion yuan at the box office.

\section{Copyright issues in cinematic adaptations of Chinese online literary works}

\section{Ambiguous boundaries for protecting the integrity of works}

According to Article 10, item 4 of the Copyright Law of the People's Republic of China: the author has the right to protect the integrity of the work, that is, 
the right to protect the work from distortion and tampering. Protecting the integrity of the work comes under the category of personal rights of the author. The essence of the adaptation of films from online literature is the behavior controlled by the right of adaptation, which comes under the category of copyright property rights. The current Chinese laws and regulations regarding the right to protect the integrity of the work have always been ambiguous. Only a conceptual provision is provided. How to apply it to judicial practice is difficult, which also makes it difficult to control the adaptation of online literary works and movies. Adapting from the text to the screen generally needs to go through the creative process of "online literary works - > movie script $\longrightarrow>$ movie production." First, film production companies should obtain the approval of the copyright owner of the online literary works to adapt its original works through legal authorization. After obtaining the legal authorization, film production companies should find screenplay writers to adapt a literary work to a script. Finally, screenwriters hand over the modified script to a film's producers, according to the requirements of the film production companies. Whether it is writing a screenplay or making a film, it is impossible to be 100 percent true to the content of the original work, so all online literary works face the issue of protecting their integrity.

Regarding the infringement standards for the integrity of works, there has always been an argument in China's judicial practice. There are two kinds of disputes: Subjective theory holders believe that any adaptation that does not conform to the original intention of the copyright owner is an infringement. However, the main discourse of objective theory is that the authorized person has already obtained the legal authorization to adapt the work, and the original copyright owner should be tolerant of the adaptation. Only when the authorized person's adaptation objectively reaches a degree that damages the reputation of the original copyright owner, then can it be considered an infringement. Chronicles of the Ghostly Tribe (with a box office of 688.3 billion yuan), adapted from the online literary work The Adventures of Three Tomb Raiders series, was released in 2015. However, in the same year, Zhang Muye, the author of The Adventures of Three Tomb Raiders sued director Lu Chuan and the film production company, claiming that the integrity of the original work had been violated. The case caused wide discussion on the protection of the complete right of ownership of the work. The court finally determined that the film did not infringe the right of protecting the integrity of the original work.

\section{The issue of the right of authorship of films adapted from online literature}

According to Article 10, item 2 of the Copyright Law of the People's Republic of China: the right of authorship is the right to indicate the identity of the author. Although the current Chinese law states that authors have the right to sign, there is no written terms and conditions for how the authors of online literary works can realize their rights and there is also a lack of relevant guidance on specific issues, such as how and where they should sign. The 
State Administration of Press, Publication, Radio, Film and Television's Film Bureau has issued the Regulation of Domestic Film Subtitles, which contains more detailed management methods for film credits, but there is no explicit stipulation on the authorship of original works of adapted films.

\section{Recommendations to improve the copyright issues of cinematic adaptations of online literary works in China}

\section{Clarify the boundaries of ownership to protect the integrity of works}

China's Copyright Law treats distortions of and tampering with original works as violations of the right to protect the integrity of works. However, there is no specific legal rules on what constitutes a distortion or tampering action. It can only be interpreted literally based on the principles of jurisprudence. Therefore, different people will have different interpretations of the problem from different perspectives.

The following elements should be comprehensively considered when judging distortion. First, protecting the integrity of works is mainly about protection of the main story line of the author's original work. In the process of adaptation, arbitrary changes to the main content and original plots are considered distortions. Second, consideration of the subjective intentional should be considered an element of infringement of the integrity of works. When an online literary work is being adapted to a movie, the adaptor or filmmaker knows but ignores the subjective intentions of the author, and this is called "intentional." Otherwise, for example, due to improper shooting methods of the adaptor or filmmaker, if the film adaptation deviates from the original shooting plan, this would not be considered distortion. Finally, the result of the actual damage should be taken as an element of infringement, such as a damage of an author's reputation or damage of the original work's social reviews.

\section{Implement rules for the authorship right of Chinese cinematic adaptations of online literary works}

Authors of online literary works possess the right of authorship. The author has the right to determine whether, when, how, what and where to sign his or her signature as a manifestation of authorship. From an economic perspective, movies adapted from online literary works are often distributed based on the popularity of the original works which already have accumulated a certain number of fans and readers. This could save a large publicity fee. For legislators, improving the implementation details of the right of authorship of adapted films is also in accordance with the legislative purpose of promoting the development of online literary works. In practice, the exercise of the right of authorship often involves the order of appearance of names of authors and screenwriters in the credits of cinematic adaptations of online 
literary works. The implementation rules on the right of authorship should be more detailed on this issue.

\section{Establish a film copyright option trading system}

A film copyright option trading system refers to the situation when a film production company and an author of an online literary work should sign a copyright transaction agreement for a certain period of time. Thus, within the agreed period of time, the film production company has priority when the author decides to sign a License Agreement. The nature of this agreement is an option priority agreement, during which time the film production company only needs to pay a small fee to secure the development of the cinematic adaptation project. If the development is all going well, the final copyright licensing agreement can be negotiated between the author and the production company with a full copyright fee in accordance with the priority agreement. If the development of the project is not going well, the film production company could abandon the project and lose only a small fee. For authors, on the other hand, signing a film copyright option agreement is only transferring the priority of the issuing the copyright of their work to others, and the copyright is still theirs. Thus, this can prevent film production companies from using online authors' work without their full authorization.

\section{Conclusion}

The numbers of cinematic adaptations of online literary works have increased rapidly in recent years in terms of both quality and quantity. Online literary works provide more high-quality scripts for the Chinese film industry. Their established popularity offers a guarantee of the box office of their cinematic adaptations, thus contributing to the prosperity of the film market. At the same time, the issue of ambiguous boundaries to protect the integrity of works and the issue of the exercise of the authorship right also limit the further development of the industry. Clearly defining the legal boundaries of the right to protect the integrity of original works, and improving the implementation details of the authorship right for online literary works, together with the establishment of a film copyright option trading system, will consolidate a strong foundation for the future development of Chinese online literary works.

\section{Bibliography}

Guobin, C. (2014). Theory and Cases of Copyright Law. Peking: Peking University Press. 